city into the water is the goal of 'New Aqueous City', which covers Sunset Park, Bay Ridge and Staten Island. Designers nArchitects' solution is to build an archipelago of concrete islands connected by inflatable storm barriers that accumulate silt and provide resilience against storm surges. In 'Water Proving Ground', LTL Architects propose a series of landscaped finger-shaped piers for the zone that includes Liberty State Park and the Statue of Liberty.

Curator Barry Bergdoll of MoMA hopes that the projects will be realized: "I don't want them to become like [French architect EtienneLouis] Boullée's late-eighteenth-century paintings in which a seemingly impossible future is projected. We want them to percolate into real projects or into public policy."

Josie Glausiusz is a journalist based in New York.

\title{
Q\&A: John Sims on mathematical art
}

While pursuing his doctorate in dynamical systems, John Sims was drawn to explore the connections between mathematics and art. Now curating a year-long series of maths-art shows at the Bowery Poetry Club in New York City, the conceptual artist explains the cultural significance of maths.

\section{What is mathematical art?}

It is art that embraces the spirit, language and process of mathematics. Both maths and art are concerned with truth, but they differ in their ways of searching for it. Maths uses analysis and proof; art uses the senses and emotions. But maths can harness the spirit of creativity and art can be analytical. Together they form a great alliance for understanding the world around us.

\section{How did you come to straddle both worlds?}

I grew up in Detroit, Michigan, and became interested in maths through a high-school science-fair project on Pythagorean triples. It was in graduate school that I started to connect maths and art. I taught a calculus course where I allowed the students to make a 'cheat sheet' of notes and formulae to take into the exam. One was visually stimulating, so I bought it. Later, I met mathematician John Horton Conway and sculptor Brent Collins who got me excited about visual maths and art. Soon after, I went to Ringling College of Art and Design in Sarasota, Florida, to develop a maths curriculum for art students.

\section{Why run a series of maths-art shows this year in New York City?}

The aim of the Rhythm of Structure series is to create an opportunity for call-and-response across maths, art and poetry - where mind meets hand meets heart. The hope is to balance the emptiness of pop culture with work that encourages deeper thinking. Nine exhibitions deal with the geometric, conceptual and social aspects of mathematical art. The geometry series included works by mathematicians Mike Field, Davide Cervone and Carlo Séquin. Another show examined how statistics can be used to distort the truth. The current exhibition includes a large geometric drawing by the late artist Sol LeWitt and a response to it by artist Adrian Piper, in the form of a 2-metre-square 'wall deletion'

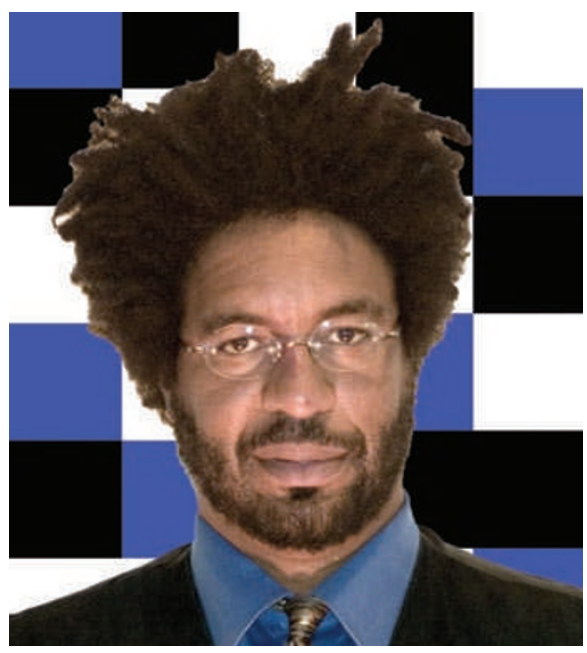

that exposes beam and brick. Mark Strand, the former US Poet Laureate, responded to the pairing in verse.

\section{Can art be useful in teaching maths?}

Sometimes. However, I think maths education is failing marginalized groups such as artists. It would be better if maths was presented less as a slave to science and more as a partner to art. Our next set of shows engages students and teachers. A class at the Brooklyn Academy of Science and the Environment is preparing a giant tessellation, inspired by M. C. Escher, that will cover a wall. Later, we will open that wall to mathematicians and maths educators, who will use the language of maths to create graffiti that will let them see their own formal symbols as objects of art, challenging the distinction between the two fields.

\section{Do views of maths differ across cultures?}

Ethnomathematics is the study of how maths is embedded in culture. One can ask how the prevailing ideas of a culture have shaped its maths. Or one can search for maths in cultural artefacts, such as the patterns in Native American basket weaving or the fractals that are said to be found in
Jackson Pollock's paintings. Paulus Gerdes, an educator and mathematician from Mozambique, has written extensively on how native mathematical thinking can inspire contemporary work. I have translated a knot diagram that Gerdes designed - inspired by African and Celtic sources - into a rope sculpture. For the last show of the series, we will create a wall of mathematical quilts from all over the world.

\section{What will you work on next?}

I am finishing a project featuring 13 quilts based on visualizations of pi and Pythagorean triples, in collaboration with Amish quilters from Sarasota. After that, I am developing an online virtual Museum of Mathematical Art.

\section{Who has influenced you?}

I am inspired by Pythagoras, who saw maths sitting at the centre of art, life and nature. I admire the work of the sixteenth-century painter Albrecht Dürer, particularly his use of magic squares [number grids in which every row, every column and the diagonals sum to the same constant]. I like the way that M. C. Escher was able to draw on the tradition of Islamic geometric art in a representational context, and I like his lithograph of an impossible waterfall inspired by the work of British mathematician Roger Penrose. In the conceptual realm, I like the surrealist artist Marcel Duchamp for his subversive audacity. However, my greatest influence is the unfolding system of structures, patterns and cycles of nature itself.

Interview by Jascha Hoffman, a writer based in San Francisco, California.

e-mail: jascha@jaschahoffman.com

Rhythm of Structure: Mathematics, Art, and Poetic Reflection Bowery Poetry Club, New York City Until 30 August 2010. See go.nature.com/ZCUbdS for details. 